At the first level of fat incorporation (3 points), the feed conversion ratio was remarkably improved by 8.5 p. 100 . The body composition was not modified.

At the second level of fat incorporation (6 points) the significant improvement in feed conversion ratio was only 4.3 p. 100 as compared to the first level. The ratio was then close to that obtained with maize.

The body composition was poorer, the fat deposition increasing with the rise in the dietary fat content - at that level the pigs were not able any more to valorize the fat.

In terms of quality, the composition of the fat depots was rather similar from one diet to another. With 6 p. 100 animal fat in the diet, the fat deposited was less saturated. Hence, it may be assumed that with a high fat supply and a restricted feeding, pigs use preferentially saturated fatty acids to satisfy their energy requirement while they deposit insaturated tatty acids.

\title{
Nutritional value of triticale for pigs : comparison with wheat, rye and protein-rich maize
}

\author{
D. BOURDON, J.M. PEREZ
}

I.V.R.A., Station de Recherches sur l'Elevage des Porcs, Centre de Rennes-Saint-Gilles, F 35590 L'Hermitage

The energy and protein value of different lots of triticale was estimated in growing pigs during two digestibility trials :

- in trial 1, a variety of triticale (13.4 p. 100 T.C.P./D.M.) was compared with a feeding wheat of the Mary Huntsman variety (14.8 p. 100 T.C.P./D.M.);

- in trial 2, two varieties of triticale (532-4 and ClerCal-43) with a low T.C.P. content (10.1 p. 100 D.M.) were compared with rye $(9.0$ p. 100 T.C.P./D.M.) and with a sampie of protein-rich maize (12.0 T.C.P./D.M.).

Eight castrated male pigs with a mean live weight of $31.5 \mathrm{~kg}$ (trial 1) and 16 castrated male pigs with a mean live weight of $31.2 \mathrm{~kg}$ (trial 2) were distributed into groups of 4 pigs per experimental diet and housed in individual pens. They received simplified diets only based on cereal ( 97 p. 100). Total faecal collection was made during 10 consecutive days.

With a rather steady gross energy content (4334 $\mathrm{kcal} / \mathrm{kg}$ D.M.), the mean energy value of triticale for pigs was $3725 \mathrm{kcal}$ D.E. $/ \mathrm{kg}$ D.M. (ranging from 3617 to $3803 \mathrm{kcal}$ ), i.e. a value located between that of rye $(3650 \mathrm{kcal})$ and that of wheat $(3850 \mathrm{kcal})$. Its mean apparent digestibility coefficient $(86$ p. 100$)$ close to that of maize $(86$ to 87 p. 100) was also located between that of rye $(85 \mathrm{p} .100)$ and that of wheat $(87$ to $88 \mathrm{p}$. 100).

The mean protein digestibility coefficient of triticale $(78.7 \mathrm{p} .100)$, close to that of maize $(79$ p. 100), was also located between that of rye $(70 \mathrm{p} .100)$ and that of wheat (85.5 p. 100).

Except the advantage of a 15 p. 100 increase in its protein content $(12$ p. 100 versus 10.4 p. 100), the nutritional characteristics of maize BRUEX H.T.V. 216, were similar to those of normal maize : $3950 \mathrm{kcal}$ D.E. $/ \mathrm{kg}$ D.M., apparent digestibility coefficient of energy and protein of 86 p. 100 and 79.7 p. 100, respectively. 